\title{
Comparison of the shear bond strength of self-adhesive resin cements to enamel and dentin with different protocol of application
}

\author{
Mohammad Javad Moghaddas ${ }^{1}$, Zahra Hossainipour ${ }^{2}$, Sara Majidinia ${ }^{3}$, Najmeh Ojrati ${ }^{4}$
}

${ }^{1}$ Department of Operative Dentistry, School of Dentistry, Mashhad University of Medical Sciences, Mashhad, Iran

${ }^{2}$ School of Dentistry, Mashhad University of Medical Sciences, Mashhad, Iran

${ }^{3}$ Dental Materials Research Center, Mashhad University of Medical Sciences, Mashhad, Iran

${ }^{4}$ Postgraduate Student of Operative Dentistry, School of Dentistry, Mashhad University of Medical Sciences, Mashhad, Iran

\section{Type of article: Original}

\begin{abstract}
Aim: The aim of the present study was to determine the shear bond strength of self-adhesive resin cements to enamel and dentin with and without surface treatments, and compare them with conventional resin cement as the control group.

Methods: In this experimental study, buccal and lingual surface of the thirty sound human premolars were polished in order to obtain a flat surface of enamel (E) in buccal, and dentin (D) in lingual. Sixty feldspathic ceramic blocks $(2 \times 3 \times 3 \mathrm{~mm})$ were prepared and randomly divided into six groups $(\mathrm{n}=10)$. Each block was cemented to the prepared surface ( 30 enamel and 30 dentin surface) according to different protocol: E1 and D1; RelyX ARC as control group, E2, D2; RelyX Unicem, E3, D3; acid etching +RelyX Unicem. The specimens were termocycled and subjected to shear forces by a universal testing machine at a cross head speed of 0.5 $\mathrm{mm} / \mathrm{min}$. The mode of fracture were evaluated by stereomicroscope. Data were analyzed with descriptive statistical methods using SPSS version 15. One-way ANOVA, and post hoc Tukey tests were used to compare bond strengths between the groups with different adhesives at $\alpha=0.05$.

Results: Statistical analysis showed no significant differences within the enamel subgroups, but there were significant differences within the dentinal subgroups, and statistically significant differences were found between the groups D1and D3 ( $p=0.02)$. Comparison between similar enamel and dentinal subgroups showed that there was a significant difference just between the subgroups E3 and D3 ( $p=0.01)$.

Conclusion: Elective etching of enamel did not lead to significant increase in the shear bond strength of RelyX Unicem in comparison to RelyX ARC. On the other hand, elective etching of dentin reduces the bond strength of RelyX Unicem with the dentin.

Keywords: Dentin, Dental porcelain, Resin cement
\end{abstract}

\section{Introduction}

In modern dentistry, feldspathic porcelains are routinely used due to their high aesthetic appearance for cosmetic improvement of unsightly anterior teeth; however, these restorations must be bonded to the natural tooth surface using adhesive resin cement due to their inherent weakness. The fracture strength of these materials is significantly reduced with a compromised bond (1). Good cement should provide sufficient bond strength to maintain the restoration in position even at high masticatory load (1). Various types of cements are available, including total-etch resin cement which is a multi-step adhesive system. They are technique sensitive and time-consuming $(2,3)$. In an attempt to simplify the application procedures, the self-etching adhesive system was developed in which the smear layer was preserved and altered (4). With this adhesive system, the primer and the bonding agent can be applied to the tooth without prior etching and rinsing of the tooth $(1,5)$. Self-adhesive resin cements first became available in

\section{Corresponding author:}

Najmeh Ojrati, Department of Operative Dentistry, School of Dentistry, Mashhad University of Medical Sciences, Mashhad, Iran. Tel: +98.9155026303, Email: ojratin921@mums.ac.ir, sara_majidinia@yahoo.com

Received: January 04, 2017, Accepted: May 17, 2017, Published: August 2017

iThenticate screening: May 11, 2017, English editing: June 17, 2017, Quality control: July 12, 2017

(C) 2017 The Authors. This is an open access article under the terms of the Creative Commons Attribution-NonCommercialNoDerivs License, which permits use and distribution in any medium, provided the original work is properly cited, the use is non-commercial and no modifications or adaptations are made. 
2002. They are also called all-purpose, multipurpose or universal resin cements. These cements are capable of binding to dental tissues without the prior use of a bonding adhesive (6). This self-adhesive cement consists of multifunctional acid methacrylate (carboxylic or phosphoric) (7), which can demineralize the dentine due to its acidity, and at the same time, the resin infiltrates the dentine matrix forming a hybrid layer with resin tags without prior removal of the smear layer. In other words, it modifies the smear layer to facilitate the formation of bond instead of removing it (4). However, a study reported that self-adhesive cement was not able to demineralize/dissolve the smear layer completely, and hence the hybrid layer was not fully formed (8). There is increasing interest in self-adhesive resin cements since it is possible to attain adhesion to the dental surface without the need to pre-treat the surface, and only a single step application is needed (9). Though, there are inconsistent views regarding the enamel bond strengths of indirect restorations using self-adhesive resin cements (10-13) Bond strength to the enamel can be negatively affected by the acidity of non-rinsed acidic primers $(14,15)$. Pre-treating the dental surface with phosphoric acid before applying the self-adhesive resin cements has been known to improve bonding $(16,17)$. But, pre-treatment of the enamel with acid has been questioned regarding its effectiveness $(18$, 19). On the other hand, pre-treatment with acid etching may negatively affect the bond strength of indirect restoration to dentin due to over etching of dentin caused by acid etch procedure and acidic primer of self-adhesive cement, which may produce an unsupported collagen layer and facilitate the degradation of hybrid layer. Thus, this study aims to compare and evaluate the shear bond strength of self-adhesive resin cements to dental enamel and dentin with and without surface treatments, and compare them with conventional resin cement as the control group.

\section{Material and Methods}

This in vitro study was carried out at Mashhad Dental School. The duration of this study was six months.

\subsection{Preparation of the feldspathic porcelain block}

A total of 30 feldspathic porcelain blocks (Ceramco, Dentsply, USA), measuring $3 \times 3 \times 2$, were prepared in a porcelain oven (VITA VACUMAT $40 \mathrm{~T}$, VITA Zahnfabrik, Germany) as per the manufacturer's instructions. Using 600 -grit silicon carbide paper (3M ESPE, St. Paul, MN, USA), each of the surfaces of the porcelain samples was polished under water cooling. In order to create surface roughness in all the samples, an intraoral air abrasion device (Microblast, Dental, Microblaster, Denmark) was used to blast $50-\mu$ aluminium oxide particles at a pressure of 50 bars, while placing the device tip $10 \mathrm{~mm}$ from the sample's surface for ten seconds $(20,21)$. The porcelain surfaces were exposed to $9.6 \%$ hydrofluoric acid for two minutes and then dried with a drying agent (Dry-Rite, pulp dent, USA) to facilitate the drying process. At this stage, the interfacial silane material (Pulpdent, Watertown, USA) was applied on the dried surface for sixty seconds and air-dried. Then, two layers of etch-and-rinse adhesive (Adper Single Bond 2, 3M, ESPE, St. Paul, MN, USA) were applied.

\subsection{Preparation of the teeth samples}

Thirty sound and freshly extracted maxillary premolars were selected for the study. Any calculus deposits and soft tissues were removed with a periodontal scaler. Subsequently, they were stored in $0.1 \%$ thymol solution until use. The teeth were randomly divided into two major groups on the basis of the enamel or dentinal substrate. After mounting all the samples with cold acrylic resin, the buccal surface was prepared for enamel samples and flattened with a diamond disk to form a flat surface with the same surface roughness, and the palatal surface was prepared for dentin samples with 15 -second cutting with a diamond disk, and then the standard smear layer was produced by removing a thin layer of the surface by using a 600-grit silicon carbide paper. The sample was examined under stereo-microscope (3D Medical systems) with (40x) magnification to check for any residual enamel in the dentinal group or any point of exposed dentin in the enamel group. These two major groups were further divided into three subgroups on the basis of the way that the cement was applied. The cements were applied as per the methodology prescribed by the manufacturer. A modified application procedure was added for the self-adhesive luting agent in both the enamel and the dentinal groups. In total, six experimental groups were prepared for testing (Table 1) as follow:

1) Group 1: enamel substrate

- Subgroup 1.1: applying of RelyX ARC

- Subgroup 1.2: applying of RelyX Unicem

- Subgroup 1.3: applying of RelyX Unicem + Etch \& Bond

2) Group 2: dentin substrate

- Subgroup 2.1: applying of RelyX ARC

- Subgroup 2.2: applying of RelyX Unicem 


\section{- $\quad$ Subgroup 2.3: applying of RelyX Unicem + Etch \& Bond}

\subsubsection{Group 1.1 and 2.1:}

The prepared surfaces of the samples were treated with 37\% phosphoric acid (Prime dent) (30 seconds for the enamel samples and 15 seconds for the dentin samples), and thoroughly rinsed and dried as per the manufacturer's instructions. Adper Single Bond adhesive was applied and then an appropriate amount of RelyX ARC cement was dispensed into a mixing pad and mixed for ten seconds. A thin layer of cement was distributed to the bonding surface of the prepared porcelain block. The cement was also applied directly onto the tooth surface. The prepared porcelain block was slowly seated and held in proper situation. Excess cement was removed immediately after seating, with each cement surface/margin light-cured for 40 seconds.

\subsubsection{Group 1.2 and 2.2:}

The prepared surfaces of the samples were cleaned with pumice, thoroughly rinsed and dried. An appropriate amount of RelyX Unicem cement was dispensed into a mixing pad and mixed for ten seconds. The rest of the procedures were similar to those followed in group 1.

\subsubsection{Group 3.1 and 3.2:}

The prepared surfaces of the samples were treated with 37\% phosphoric acid (Prime dent) (30 seconds for the enamel samples and 15 seconds for the dentin samples), and thoroughly rinsed and dried as per the manufacturer's instructions. Adper Single Bond adhesive was applied and then an appropriate amount of RelyX Unicem cement was dispensed into a mixing pad and mixed for ten seconds. The rest of the procedures were as followed in group 1. All samples underwent shearing force using a universal testing machine (Hounsfield Test Equipment, Model H5K$\mathrm{S}$, England) at a crosshead speed of $0.5 \mathrm{~mm} / \mathrm{min}$ to measure the shear bond strength of porcelain to enamel and dentin. This was achieved by setting the machine's chisel-shaped blade at the porcelain interface. (Figure1). Calculation of the bond strength values was in $\mathrm{MPa}$ and was done by dividing the bond strength values measured in Newton by the bonded surface areas of samples in $\mathrm{mm} 2$. Failure modes were determined under a stereomicroscope (SMZ 1500, Nikon, Japan) following the fracture of the samples. The data were analysed with descriptive statistical methods using SPSS (SPSS Inc. Chicago, Illinois, USA) 15/Win. One-way ANOVA and post hoc Tukey tests were used to compare the bond strengths between the groups at $\alpha=0.05$.

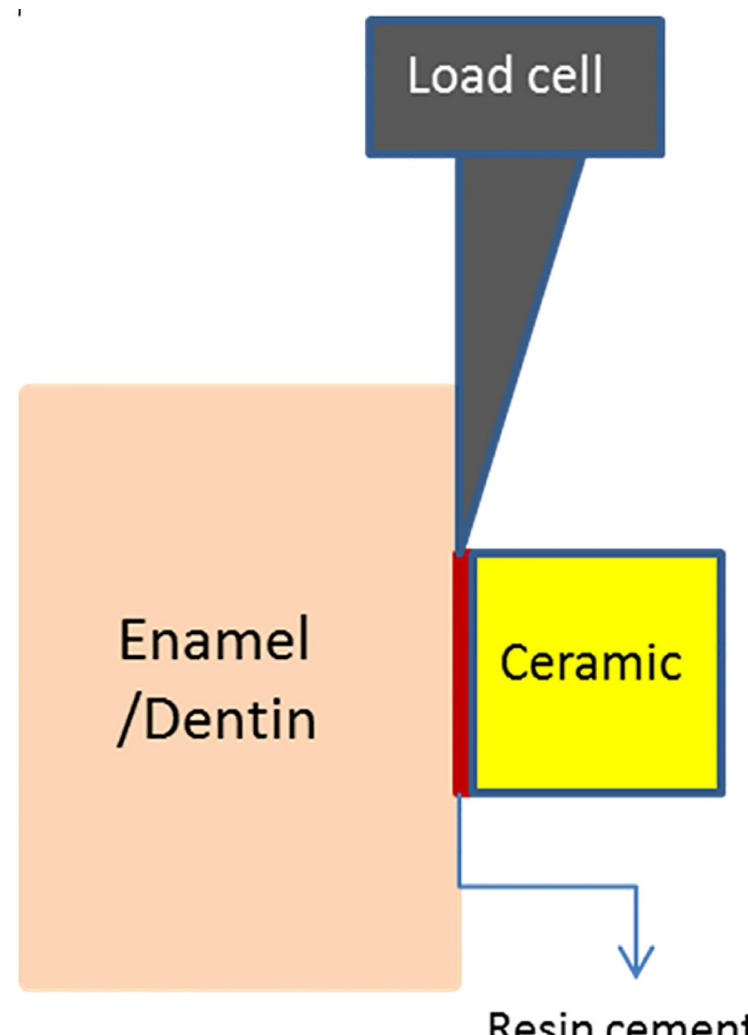

Figure 1. Schematic view of shear bond strength test 
Table 1. The mean and SD of shear bond strength for each group

\begin{tabular}{|l|l|l|l|}
\hline Groups & $\mathrm{n}$ & Mean & SD \\
\hline Enamel + RelyX ARC (1-1) & 10 & 14.2480 & 2.27914 \\
\hline Enamel + RelyX Unicem (1-2) & 10 & 13.0860 & 3.61398 \\
\hline Enamel + RelyX Unicem + Etch \& Bond (1-3) & 10 & 17.4290 & 8.32933 \\
\hline Dentin + RelyX ARC (2-1) & 10 & 12.6420 & 1.12928 \\
\hline Dentin + RelyX Unicem (2-2) & 10 & 11.0730 & 1.83647 \\
\hline Dentin + RelyX Unicem + Etch \& Bond (2-3) & 10 & 9.2680 & 3.27194 \\
\hline
\end{tabular}

\section{Results}

The values of shear bond strength for each group are shown in Table 1. The highest amount of shear bond strength was related to the group 1.3 and the least was related to the group 2.3. Statistical analysis showed no significant differences within the enamel subgroups $(\mathrm{p}=0.196)$, but there were significant differences within the dentinal subgroups ( $\mathrm{p}=0.009$ ), and statistically, significant differences were found between the groups 2.1 and $2.3(\mathrm{p}=0.02)$. Comparison between similar enamel and dentinal subgroups showed that there was a significant difference between the subgroups 1.3 and $2.3(\mathrm{p}=0.01)$ and there were no differences between the other similar subgroups. The evaluation of the mode of failure showed that in 1.1, the failures were almost mixed and were adhesive in the interface of enamel and cement, and in 1.2, 1.3 and 2.1 and 2.3, the failures were adhesive in the interface of enamel or dentin and cement. In 2.2 the failures were almost mixed.

\section{Discussion}

The results of this study reveal that the applications of total etch resin cements do not have an advantage over selfadhesive cements, with or without etch and bonding of the enamel substrate. So, the assumption that there are no differences between the bond strengths of RelyX ARC and RelyX Unicem, with or without preparing the substrate, stands accepted. This is in agreement with the other similar studies. Pekperdahci et al. also recommended RelyX Unicem for its easier and faster application technique and low technique sensitivity (22). Similar results were reported by Hikita et al, who observed that there were no differences between the application of self-adhesive and total etch luting cements (3). Vaz et al. came up with similar results, observing that both luting cements have reliable bonding (23). Viotti et al. also reported similar findings (24), as did Sakalauskaite et al. who also noted that the physico mechanical properties of conventional and self-adhesive cements were similar (25). Between self-adhesive cements, RelyX Unicem has an advantage. The base paste of this cement contains methacrylate monomers comprising of acid phosphoric groups. These monomers have a self-etching effect on the tooth surface. This effect is done with the ionisation of acid monomer with water on the enamel and the dentin surfaces. So, the hydrogen ions raise the etching effect. On the basis of the research by Munk et al., the water that is needed for the ionization of acid is present in the RelyX Unicem cement composition (26). The catalyst paste also has methacrylate monomer with alkaline fillers. The alkaline fillers in this cement can react with acidic methacrylate monomer groups, and with hydroxyapatite of the enamel and the dentin in the other site, and neutralize the composition of the setting cement $(27,28)$. Although RelyX Unicem has low PH and low surface interaction so it doesn't create specific hybrid layer and resin tags $(29,30)$, the micromechanical retention and chemical interaction of acidic monomers that contain phosphate group with HA of the tooth lead to the desirable bond strength with this cement (31). The results of the bond strength of the dentin groups showed no significant difference between the subgroups 1D and 2D. A large number of studies have shown similar dentin bond strengths between self-adhesive and conventional cements (32, 33). The amount of bond strengths of the subgroup 3D was significantly lower than $\mathrm{D} 1$. This finding shows that the etching and bonding process of dentin before application of self-adhesive cement reduces bond strength. Indeed, the synergic effect of phosphate monomers in RelyX Unicem cement and 37\% phosphoric acid cause the hyper demineralization of the dentin and exclusion of the peritubular and intertubular dentin. In the present study, after deriving the data on bond strengths, the types of destruction were measured. Except for the subgroups D2 and E1, the mode of destruction in all the groups were adhesive and at the interface of the cement and porcelain. On the basis of the findings postulated in this study and other studies, this cement's bond strength is higher with enamel than that with porcelain (34). In the subgroup D2, almost all destruction was mixed, thus showing that Unicem cement has similar bond strengths with dentin and porcelain. In the subgroup D3, most of the destruction was adhesive and showed that etching of dentin has a destructive effect on bonding (35). Other studies have shown that over-etching of dentin can weaken the hypo demineralized dentin $(36,37)$ and start de-bonding at the interface $(38)$. This in vitro study provides important information; however, these do not replace clinical trials. Furthermore, evaluation of the fractured surfaces by Scanning Electron Microscopy (SEM) was not included in the study. In order to evaluate the durability of the bond formed after simulated aging, further in vitro studies are required. The 
limitations of this study are that the universal testing machine could not produce the complex nature of the masticatory forces in the oral cavity, and the study was carried out by using extracted teeth.

\section{Conclusions}

This in vitro study was carried out to comparatively determine the shear bond strength of self-adhesive resin cements to enamel and dentin with and without surface treatments, and compare them with conventional resin cement as the control group. This study showed that there are no differences between the bond strengths of RelyX Unicem self-adhesive cement and RelyX ARC adhesive conventional cement. Elective etching of enamel does not lead to significant increase in the shear bond strength of both of the cements but elective etching of dentin reduces the bond strength of RelyX Unicem with the dentin. It is inferred from this study that surface treatment and bonding surface area determines the adhesive characteristics.

\section{Acknowledgments:}

This study was supported by a grant from Mashhad University Research Council, which is gratefully acknowledged. The results of the present study have been taken from a student thesis no 478 .

\section{Conflict of Interest:}

There is no conflict of interest to be declared.

\section{Authors' contributions:}

All authors contributed to this project and article equally. All authors read and approved the final manuscript.

\section{References:}

1) Torres CR, Pinto LQ, Leonel AG, Pucci CR, Borges AB. Interaction between total-etch and self-etch adhesives and conventional and self-adhesive resin cements. Braz J Oral Sci. 2007; 6: 1376-82.

2) Ariki EK, Pavanelli CA, Tomm A, Zogheib LV. Cementation of ceramics and indirect composite resin to enamel and dentin using different resin-based cements - Shear bond strength. RFO Passo Fundo. 2012; 17: 261-7.

3) Hikita K, Van Meerbeek B, De Munck J, Ikeda T, Van Landuyt K, Maida T, et al. Bonding effectiveness of adhesive luting agents to enamel and dentin. Dent Mater. 2007; 23(1): 71-80. doi: 10.1016/j.dental.2005.12.002. PMID: 16426673.

4) Albaladejo A, Osorio R, Toledano M, Ferrari M. Hybrid layers of etch-and-rinse versus self-etching adhesive systems. Med Oral Patol Oral Cir Bucal. 2010; 15(1): e112-8. PMID: 19767690.

5) De Munck J, Van Landuyt K, Peumans M, Poitevin A, Lambrechts P, Braem M, et al. A critical review of the durability of adhesion to tooth tissue: Methods and results. J Dent Res. 2005; 84(2): 118-32. doi: 10.1177/154405910508400204. PMID: 15668328.

6) Swartz ML, Philip RW, Day R, Johnston JF. A laboratory and clinical investigation of certain resin restorative and cementing materials. Part 1. In vitro tests on adhesive characteristics. J Prosthet Dent. 1955; 5(5): 698-704. doi: 10.1016/0022-3913(55)90098-6.

7) Zorzin J, Petschelt A, Ebert J, Lohbauer U. pH neutralization and influence on mechanical strength in selfadhesive resin luting agents. Dent Mater. 2012; 28(6): 672-9. doi: 10.1016/j.dental.2012.03.005. PMID: 22464870.

8) Monticelli F, Osorio R, Mazzitelli C, Ferrari M, Toledano M. Limited decalcification/diffusion of selfadhesive cements into dentin. J Dent Res. 2008; 87(10): 974-9. doi: 10.1177/154405910808701012. PMID: 18809754.

9) Cantoro A, Goracci C, Papacchini F, Mazzitelli C, Fadda GM, Ferrari M. Effect of pre-cure temperature on the bonding potential of self-etch and self-adhesive resin cements. Dent Mater. 2008; 24(5): 577-83. doi: 10.1016/j.dental.2007.06.012. PMID: 17659770.

10) De Munck J, Vargas M, Van Landuyt K, Hikita K, Lambrechts P, Van Meerbeek B. Bonding of an autoadhesive luting material to enamel and dentin. Dent Mater. 2004; 20(10): 963-71. doi: 10.1016/j.dental.2004.03.002. PMID: 15501325 .

11) Abo-Hamar SE, Hiller KA, Jung H, Federlin M, Friedl KH, Schmalz G. Bond strength of a new universal self-adhesive resin luting cement to dentin and enamel. Clin Oral Investig. 2005; 9(3): 161-7. doi: 10.1007/s00784-005-0308-5. PMID: 15856343. 
12) Fabianelli A, Goracci C, Bertelli E, Monticelli F, Grandini S, Ferrari M. In vitro evaluation of wall-to-wall adaptation of a self-adhesive resin cement used for luting gold and ceramic inlays. J Adhes Dent. 2005; 7 : 33-40. PMID: 15892362.

13) Behr M, Rosentritt M, Regent T, Lang R, Handel G. Marginal adaptation in dentin of a self-adhesive universal resin cement compared with well-tried system. Dent Mater. 2004; 20(2): 191-7. doi: 10.1016/S0109-5641(03)00091-5. PMID: 14706803.

14) Moura SK, Pelizzaro A, Dal Bianco K, de Goes MF, Loguercio AD, Reis A, et al. Does the acidity of selfetching primers affect bond strength and surface morphology of enamel? J Adhes Dent. 2006; 8(2): $75-83$. PMID: 16708718.

15) Pashley DH, Tay FR. Aggressiveness of contemporary self-etching adhesives. Part II: etching effects on unground enamel. Dent Mater. 2001; 17(5): 430-44. doi: 10.1016/S0109-5641(00)00104-4. PMID: 11445211.

16) Van Meerbeek B, Kanumilli P, De Munck J, Van Landuyt K, Lambrechts P, Peumans M. A randomized controlled study evaluating the effectiveness of a two-step self-etch adhesive with and without selective phosphoric-acid etching of enamel. Dent Mater. 2005; 21(4): 375-83. doi: 10.1016/j.dental.2004.05.008. PMID: 15766585.

17) Van Landuyt KL, Peumans M, De Munck J, Lambrechts P, Van Meerbeek B. Extension of a one-step selfetch adhesive into a multi-step adhesive. Dent Mater. 2006; 22(6): 533-44. doi: 10.1016/j.dental.2005.05.010. PMID: 16300826.

18) Perdigao J, Anauate-Netto C, Carmo AR, Lewgoy HR, Cordeiro HJ, Dutra-Correa M, et al. Influence of acid etching and enamel bevelling on the 6-month clinical performance of a self-etch dentin adhesive. Compend Contin Educ Dent. 2004; 25(1): 33-4. PMID: 15645878.

19) Shinchi MJ, Soma K, Nakabayashi N. The effect of phosphoric acid concentration on resin tag length and bond strength of a photo-cured resin to acid-etched enamel. Dent Mater. 2000; 16(5): 324-9. doi: 10.1016/S0109-5641(00)00024-5. PMID: 10915893.

20) Shiu P, De Souza-Zaroni WC, Eduardo Cde P, Youssef MN. Effect of feldspathic ceramic surface treatments on bond strength to resin cement. Photomed Laser Surg. 2007; 25(4): 291-6. doi: 10.1089/pho.2007.2018. PMID: 17803387.

21) Da Silva Ferreira S, Hanashiro FS, de Souza-Zaroni WC, Turbino ML, Youssef MN. The porcelain surf Influence of aluminum oxide sandblasting associated with $\mathrm{Nd}: \mathrm{YAG}$ or Er:YAG lasers on shear bond strength of a feldspathic ceramic to resin cements. Photomed Laser Surg. 2010; 28(4): 471-5. doi: 10.1089/pho.2009.2528. PMID: 19780632.

22) Pekperdahci T, Turkoz Y, Ozan O, Seker E. The effects of different adhesive agents on the shear bond strength of a self-adhesive resin cement. J Appl Biomater Funct Mater. 2012; 10(2): 149-56. doi: 10.5301/JABFM.2012.9255. PMID: 22798242.

23) Vaz RR, Hipólito VD, D'Alpino PH, Goes MF. Bond strength and interfacial micromorphology of etchand-rinse and self-adhesive resin cements to dentin. J Prosthodont. 2012; 21(2): 101-11. doi: 10.1111/j.1532-849X.2011.00794.x. PMID: 22044733.

24) Viotti RG, Kasaz A, Pena CE, Alexandre RS, Arrais CA, Reis AF. Microtensile bond strength of new selfadhesive luting agents and conventional multistep systems. J Prosthet Dent. 2009; 102(5): 306-12. doi: 10.1016/S0022-3913(09)60180-3. PMID: 19853172.

25) Saskalauskaite E, Tam LE, McComb D. Flexural strength, elastic modulus, and pH profile of self-etch resin luting cements. J Prosthodont. 2008; 17(4): 262-8. doi: 10.1111/j.1532-849X.2007.00278.x. PMID: 18086139.

26) De Munk J, Vargas M, Van Landuyt K, Hikita K, Lambretchts, Van Meerbeek B. Bonding of an autoadhesive luting material to enamel and dentin. Dent Mat. 2004; 20: 963-71. doi: 10.1016/j.dental.2004.03.002. PMID: 15501325.

27) Barcellos DC, Batista GR, Silva MA, Rangel PM, Torres CR, Fava M. Evaluation of Bond Strength of Self-adhesive Cements to Dentin With or Without Application of Adhesive Systems. J Adhes Dent. 2011; 13(3): 261-5. doi: 10.3290/j.jad.a19224. PMID: 21734960.

28) Aschenbrenner CM, Lang R, Handel G, Behr M. Analysis of marginal adaptation and sealing to enamel and dentin of four self-adhesive resin cements. Clin Oral Investig. 2012; 16(1): 191-200. doi: 10.1007/s00784-010-0501-z. PMID: 21327799.

29) Hickel R, Roulet JF, Bayne S, Heintze D, Mjor IA, Peters M, et al. Recommendations for conducting clinical studies of dental restorative materials. Science Committee Project 2/98--FDI World Dental 
Federation study design (Part I) and criteria for evaluation (Part II) of direct and indirect restorations including onlays and partial crowns. J Adhes Dent. 2007; 9: 121-47. PMID: 18341239.

30) Rosentritt M, Behr M, Lang R, Handel G. Influence of cement type on the marginal adaptation of allceramic MOD inlays. Dent Mater. 2004; 20(5): 463-9. doi: 10.1016/j.dental.2003.05.004. PMID: 15081553.

31) Ibarra G, Johnson GH, Geurtsen W, Vargas MA. Microleakage of porcelain veneer restorations bonded to enamel and dentin with a new self-adhesive resin-based dental cement. Dent Mater. 2007; 23(2): 218-25. doi: 10.1016/j.dental.2006.01.013. PMID: 16499961.

32) Sarr M, Mine A, De Munck J, Cardoso MV, Kane AW, Vreven J, et al. Immediate bonding effectiveness of contemporary composite cements to dentin. Clin Oral Investig. 2010; 14(5) 569-577. doi: 10.1007/s00784009-0327-8. PMID: 19705169.

33) Abo-Hamar SE, Hiller KA, Jung H, Federlin M, Friedl KH, Schmalz G. Bond strength of a new universal self-adhesive resin luting cement to dentin and enamel. Clin Oral Investig. 2005; 9(3): 161-7. doi: 10.1007/s00784-005-0308-5. PMID: 15856343.

34) Peutzfeldt A, Sahafi A, Flury S. Bonding of Restorative Materials to Dentin with Various Luting Agents. Oper Dent. 2011; 36(3): 266-73. doi: 10.2341/10-236-L. PMID: 21740244.

35) Pereira PNR, Okuda M, Sano H, Yoshikawa T, Burrow MF, Tagami J. Effect of intrinsic wetness and regional difference on dentin bond strength. Dent Mater. 1999; 15(1): 46-53. doi: 10.1016/S01095641(99)00013-5. PMID: 10483395.

36) Yoshikawa T, Sano H, Burrow MF, Tagami J, Pashley DH. Effects of dentin depth and cavity configuration on bond strength. J Dent Res. 1999; 78(4): 898-905. doi: 10.1177/00220345990780041001. PMID: 10326734.

37) Nakabayashi N, Watanabe A, Arao T. A tensile test to facilitate identification of defects in dentin bonded specimens. J Dent. 1998; 26(4): 379-85. doi: 10.1016/S0300-5712(97)00021-3. PMID: 9611944.

38) Hashimoto M, Ohno H, Kaga M, Sano H, Tay FR, Oguchi H, et al. Over-etching effects on micro-tensile bond strength and failure patterns for two dentin bonding systems. J Dent. 2002; 30(2-3): 99-105. doi: 10.1016/S0300-5712(02)00004-0. PMID: 12381409. 